\section{The Intersections of Latino Identity: Religion, Group Consciousness, and Immigration Policy}

\author{
Rebecca Gonzalez \\ Senior, Political Science
}

\section{Introduction}

Minority political participation becomes more salient as these populations become more intertwined in the socio-economic fabrications of society. Rhetoric highlighting the importance of obtaining the minority vote has also become more pronounced (Alvarez \& Bedolla, 2003; Chavez 2013; Garcia 2017; Kelly 2008) and can be observed by the most recent presidential elections of Barack Obama and Donald Trump. In both cases, the success of these candidates has been attributed to their ability to mobilize minority populations (Alvarez \& Bedolla, 2003). Just as the tangible political implications of these growing populations increases, scholarship has also followed, asking questions of what and why these groups vote the way they do.

The theory of group consciousness serves as an explanation for what and why certain racial groups engage in distinct political behavior. Group consciousness is defined as the recognition of common concerns and values among race groups that mobilize mutual political preferences (Dawson 1994;McClain et.al 2009). Though research on this subject is diversifying, it is still applied most within the context of African Americans. Pioneer discussions of Latino group consciousness have emerged recently, however given difference of pan ethnic relations between Latino subgroups, there are still pronounced questions related to Latino political participation. Considering the youth of group consciousness theory overall, the dimensions of this study are also largely undiscovered as they are centrally applied to the context of race and ethnicity.

This paper applies the theory of group consciousness to the context of religion, arguing that religious group consciousness influences political preference. By investigation Latino policy preferences on immigration, I find that religious group consciousness plays some role in mobilizing political opinion though the salience of this function is weak in comparison that of race. Specifically, this preliminary analysis finds that behavioral identity indicators of religious group consciousness are more salient indicators than those of affiliation when operationalizing religious group consciousness. By distinguishing better indicators of measuring religious group consciousness, I hope to provide a foundational knowledge that may be utilized in future research on the subject.

\section{Literature Review and Theoretical Framework}

Studies on the subject of religious affiliation and political preference have a robust presence in social science literature. Questions of how religion may impact political behavior are considered by scholars such as Vega (2014), McDaniel \& Nooruddin \& Shortle (2011), Jones-Correa (2001), and Layman (1997). The focus of current scholarship largely pertains to correlations between religiosity and conservative political behavior, specifically, in the context of Anglos and Blacks rather than Latinos. In the Latino context, Jones-Correa (2001), Kelly \& Kelly (2005), and Kelly \& Morgan (2008) begin to examine religious political behavior, yet the studies do not investigate religious policy 
preferences with a focus on immigration. On the subject of immigration and Latino politics, Hood, Morris, \& Shirkey (1997), de la Garza (1998), and Garcia (2017), provide key insights to conditions shaping Latino interests, both diverging and converging, on the issue. Further, on the subject of group consciousness Dawson (1994), Sanchez (2006), and Garcia (2017) provide a base conceptualization of this consciousness among Latinos as they consider how group identity mobilizes certain policy preferences. Seeking to interpret the salience of religious identity among racially linked Latinos, the subject of immigration is being chosen because of its intersectional significance. Since immigration is an issue that influences all Latinos (Garcia 2017), testing these policy preferences alongside religious affiliation provides a theory of political participation grounded in the concept of religious group consciousness. The current literature on religious affiliation and political behavior is being largely separated from scholarship on Latino policy preferences and immigration. It is my intent to analyze the literature on these three subjects; immigration, religious political behavior, and group consciousness in order to provide a working foundation for my argument on the salience of religious group consciousness in the context of Latinos.

\section{Religious Implications for Political Behavior}

The role of religion in shaping political preference is further asserted in modern literature by the findings of Verba, Schlozman, Brady \& Nie (1993), and Geoffrey Layman (Layman 1997; Layman \& Carmines 1997). Verba, Schlozman, Brady \& Nie find that if a participant "joins a church and begins to attend services weekly and to devote an additional three hours a week to other church activity, this person will perform approximately two more church skill-acts (including tithing or volunteering), which will produce an increase of political acts" (Verba \& Schlozman \& Brady 1993 pg. 285). Layman builds on previous findings as well and observes the role of churches in increasing political participation among Blacks (Verba, Schlozman, and Brady 1993). He finds various differences in partisanship based on degrees of religious observance. Orthodox observers, favor a stricter adherence to Christian belief and also tend to lean in favor of the Republican Party, while more religiously liberal respondents support the Democratic Party (Verba et.al 1993). They examine the changes of church denominational affiliations over time, and interpret the influence of this change in dictating political partisanship, specifically by measuring presidential vote choices. Layman identifies the salience of religious affiliation in political participation, finding that "highly religious individuals have consistently been more likely than their less religious counterparts to identify with the GOP," further asserting that American political alignments are increasingly being shaped by the orthodoxy of religious beliefs (Layman 1997 pg. 301). This seminal piece emphasizes the importance of cross denominational considerations when predicting the influence of religion in predicting political partisanship.

\section{Religious Implications for Political Behavior and Latinos}

Literature that focuses on political partisanship and religion still rarely apply these models to ethnic groups beyond Anglos and Blacks. "Overall we know little about the political implications of Latino religion," (Kelly \& Kelly 2005 pg 88) and thus Verba et.al (1993), Jones-Correa (2001), Kelly \& 
Kelly (2005), and Kelly \& Morgan (2008) work towards applying questions of religious affiliation and partisanship to the Latino context. Verba et.al (1993) finds that religious affiliation and church attendance explain varying levels of participation among Latinos in particular, arguing that Catholic affiliated Latinos have lower levels of participation. Jones-Correa and Leal (2001) builds on this model and applies-these findings to Protestant practicing Latinos, finding that Protestant Latinos are more likely than Catholics to participate. Similarly, Kelly \& Kelly (2005) measure differences in Latino partisanship further building upon previous scholarship. They apply measures of religious behavior, emphasizing the psychological role of churches apart from just religious attendance that measures the contextual role of churches in disseminating political information. Further, work on partisanship within the Latino context supports the notion that Evangelical Protestant Latinos have a strong and positive partisanship identification with the Republican Party (Kelly \& Morgan 2008). Together, these texts work to identify the salience of religious affiliation in the Latino context, supporting the notion that Latinos identifying as strong Catholics or Protestants also lean conservative in political behavior. This validates the base assumption of this paper, proposing that Latinos with strong religious observance in either religious sect may also have conservative views when it comes to immigration policy.

\section{Religious Implications for Immigration Policy}

Literature on the subject of immigration does not consider religious ideology in forming conservative or liberal policy preferences, specifically in the framework of Latinos. In the context of American Latinos, McDaniel, Nooruddin \& Shortle (2011) still provide evidence of religious affiliation and its effect on immigration policy preferences. They develop hypotheses arguing that attitudes of immigration are being affected by conservative perspectives of civil religion, termed as 'Christian Nationalism'. They find that, "members of religious groups are more likely to oppose immigrants, this is particularly true of Evangelical Protestants, and the source of opposition to immigrants is rooted in symbolic politics, specifically a concern that immigrants threaten "American values"' (McDaniel, Nooruddin \& Shortle 2011 pg. 223). Knoll (2009) examines religion and immigration policy as well finding that those who attend religious services more frequently are likely to support liberal immigration reform policy. Some of the more vocal protests of immigrant measures have recently come from the leaders of various religious organizations (Knoll 2009 pg. 313). Knoll's findings present diverging results from that of McDaniel et.al, further illustrating undiscovered caveats for examination within the current discourses on religion and immigration policy. Though concepts of religious affiliation, immigration, and political behavior have been combined in these studies, still there is disconnect between applying these concepts in the Latino contexts.

\section{Latino Group Consciousness and Perspectives on Immigration}

The study of Latino group

consciousness has a relatively new appearance in literature on group consciousness. Seminal pieces are largely attributed to the works of Gabriel Sanchez (2006; 2008), Atiya Stokes (2003), and Natalie Masuoka (2006). Though original studies of group consciousness, such as those by Miller, A. H., Gurin, P., Gurin, G., \& Malanchuk, O. (1981) and Dawson (1994) may be applied to the Latino context, since these 
groups face different cultural, economic, and social dynamics. Therefore, I will focus on the studies done on Latinos specifically considering these contextual differences. Gabriel Sanchez (2006) explores Latino group consciousness across different modes of political participation and Latino-specific activities. He finds that group consciousness among Latinos has a positive effect on mobilizing political participation (Sanchez 2006). Though he does not explore whether Latino group consciousness impacts voter specific choices and decision of partisanship, his analysis provides a solid framework for further exploration of Latino policy preferences such as the topic of immigration (as is the aim of this study).

Ativa Stokes specifically analyzes Latino political participation and group consciousness across various pan-ethnic Hispanic identities. She finds that different dimensions of group consciousness mobilize different subgroups of Latinos, specifically polarized power dynamics in government “increases Mexican political participation, systemic blame increases participation among Puerto Ricans, and systemic blame and group identification increase political participation among Cubans" (Stokes 2003). Additionally, Masuoka (2006) questions pan-ethnic group consciousness amongst Latinos and Asians, finding that "although both Asian Americans and Latinos share many similar experiences, such as immigration, language differences, and acculturation processes, these factors are found to play differential roles for perceptions of collective identity" (Masuoka 2006). This knowledge suggests that different factors within ethnic communities may impact one's sense of group consciousness. I consider such a factor to be religious identity though it has not been considered in prior studies of group consciousness.

Working towards filling gaps in literature, Vargas, Sanchez, and Valdez (2017) analyze the influence of immigration policy on perspectives of linked fate among Latinos. They find that both punitive and beneficial immigration laws such as the Illegal Immigration Reform and Immigrant Responsibility Act of 1996, The Personal Responsibility and Work Opportunity Reconciliation Act of 1996, and the Anti-Terrorism and Effective Death Penalty Act (Garcia 2017 pg. 187) increase indicators of linked fate. Further, John Garcia (2017) examines Latino immigration policy preferences in a discussion of Latino community perceptions. He begins the dialogue discussing the importance of Latino policy preferences as the population of Latino voters in America is increasing. Unsurprisingly, the Hispanic vote has gained momentum just as both direct and indirect implications of punitive immigration policies have negatively affected these populations, mobilizing them to action. Such policies include those that are actively creating a 'militarization' of the U.S - Mexico Border implicitly framing undocumented immigrants in criminal terms (Garcia 2017 pg. 175). Additional policies include the immigration reform legislations of the 1990's under George H.W. Bush that increased funding to the Border Patrol, inherently increasing apprehensions of both undocumented and documented Latino immigrants. On a legislative dimension, these policies have mobilized the few however increasing minority representatives resulting in salient political organizations such as the Congressional Hispanic Caucus (Garcia 2017 pg. 171). De la Garza, offers a perspective of the nature of Mexican American identity 
arguing that the large and continuous nature of Mexican immigration distinguishes or separates this subgroup perspective from that of other Latinos. He adds that the constant reminder of Mexican immigrants due to their steady influx, elicits a stronger sense of community within Mexican Americans when examining their politico-social perspective. He powerfully concludes on the subject of group identity that although shared empathy for immigrants is salient, "Mexican Americans can influence policies that concern Mexico, but this influence will be shaped not out of a loyalty to Mexico but instead out of their own interest in US policy" (De la Garza 1998). This suggests that on the subject of immigration, though Latinos vote based on their racial identity, there are still clear differences in preferences between individual ethnic subgroups.

\section{The Theoretical Underpinnings of Religious Group Consciousness}

Knowledge on the study of group consciousness is being largely attributed to the work of Michael C. Dawson (1994). In his book Behind the Mule: Race and Class in African American Politics, Dawson examines the salience of racial identity in political participation among African Americans. In his analysis, he finds that perceptions of group interest play a more significant role in shaping partisanship and political strategy than class interest. He finds evidence for the salience of race based group interests in predicting partisanship among Blacks which he coins as group consciousness. Building on this concept, McClain, Carew, Walton, and Watts (2009) define group consciousness as "in-group identification politicized by a set of ideological beliefs and group's social standing" (McClain et.al 2009 pg. 476). The key separation of this meaning from that of group identity, which is defined as an individual's psychological awareness of belonging to a group (McClain et.al 2009), is the notion that group consciousness mobilizes certain political preferences. A multitude of studies have applied group consciousness to various races (McClain et.al 2009; McClain \& Stewart 2013; Garcia 2017; Sanchez 2006; Junn 2008, Masuoka 2006) yet this concept has not been applied to religious identity. In this analysis, I work towards applying McClain's definition of group consciousness to the case of religion, analyzing the salience of religion as an intersectional identity such as race and class are. I utilize Latino perceptions of immigration policy as a surrogate for this comparison.

Given that immigration policy intersects both race and religious identities in the Latino context (McDaniel \& Nooruddin \& Shortle 2011; Garcia 2017; Vargas \& Sanchez \& Valdez 2017), I believe it is a justified case to examine the prospect of religious group consciousness. Latinos constitute a large immigrant population (Pew Research Center 2014) and regardless of citizenship status, this pan ethnic population faces stereotypes pertaining to the image of being "illegal aliens" (Chaves 2013). This provides positive and negative implications for the use of immigration policy as a measure for the salience of religious group consciousness. Though Latinos constitute a large population of immigrants and it is plausible that as a racial group they will benefit more from liberal immigration policies, those Latinos who do not have a shared sense of identity may interpret immigrants as an economic threat. Since linked fate, or the shared sense of sociopolitical connectedness via race, is being argued by Dawson (1994) to transcend economic threats and class differences, it is important to consider this variable in the measure of religious 
identity. The logic is that Latinos who have a sense of linked fate may also have liberal perceptions of immigration given that Latinos benefit or suffer from this form of policy. Considering this shared sense of racial identity, if Latinos claim conservative perceptions of immigration reform, it can be assumed that other considerations, such as religious identity, may be of salient concern.

Immigration is a subject greatly influenced by race and religious perceptions (McDaniel \& Nooruddin \& Shortle 2011; Garcia 2017; Vargas \& Sanchez \& Valdez 2017). Latinos are a group affected by the racial implications of immigration policy and also constitute a large majority of Catholic and Christian followers. 55\% of the Latino population identifies as Roman Catholic and 22\% identifies as Protestant in 2013 (Liu, Pew Research Center). This percentage constitutes the majority of the total Latino population that identifies with some denomination of religion. As previous studies have suggested, religious affiliation mobilizes common patterns of political behavior (Verba \& Schlozman \& Brady 1993; Layman 1997; Layman \& Carmines 1997). This suggests that religion not only shapes perceptions of group identity but also produces a sense of group consciousness by which these groups mobilize towards political action in accordance to McClain's definition.

Religion is an intersectional identity often neglected in studies though it does reflects a shared sense of in-group identity (McDaniel \& Nooruddin \& Shortle 2011). Past research ignores the conceptualization of religion as a salient identity amongst its followers and views religion as a form of church affiliation. Though Jones Correa (2001) and Kelly \& Kelly (2005) begin a framework of analyzing religion as a form of behavioral identity rather than just an affiliation to a certain church, and they do so within the Latino context, they do not apply this influence specifically to the subject of immigration. Likewise, though Vega (2014) begins to analyze Latinos who 'disrupt the tenet of ethnic solidarity' on the subject of immigration, she does not factor in religion.

As 1 Corinthians 12:13 suggests, once a member of the body of Christ, one is "baptized by one Spirit so as to form one body" (NIV) or one common identity in Christ. This group identity does not manifest itself by primarily physical mutual characteristics as race has been socially constructed to do. Rather religion forms group identity through the spiritual base of common moral beliefs. A common moral identity "provides a cultural framework that helps individuals understand what actions are acceptable and what are not and therefore plays a central role in shaping social and political attitudes" (McDaniel \& Nooruddin \& Shortle 2011). This is particularly demonstrated in the discourse on abortion by which Christian and Catholic followers have common moral standings that result in political preferences leaning traditionally conservative. For the case of abortion policy, religious observers share the ethical principle that "life is sacred," and they abide by this notion in their everyday lives (Lopez 2012 pg. 513). This has affected their political attitudes towards Democrats as they find that the Republican Party stands on the pro-life side of the debate. Religious group consciousness is being conceptualized differently than race in that it does not necessarily mobilize political activity based on a shared sense of discrimination, but rather on a shared sense of group goals in terms of biblical and spiritual fulfillment. The common goal of the church as outlined by biblical text is to "go therefore and make disciples of all nations, 
baptizing them in the name of the Father and of the Son and of the Holy Spirit" (Mathew 28:19 NIV Bible). Within the political arena, this goal translates into support for conservative policies since these tend to align with traditional Christian/Catholic values. The Republican Party in general is attractive to Christian/Catholic identifying populations because of the Party's vocal political expression of certain values fundamental to the faith. Given that the majority of Christians/Catholics align more with the Republican Party, and Republicans favor stricter border policies, I expect Latinos who identify as strong religious observers to have stricter perspectives of immigration policy. If these Christian Latinos who identify as also having a sense of linked fate with the Hispanic community, then it is being proposed that religion is a salient identity above race in this political discourse.

\section{Hypothesis}

Understanding the plausible influences of religious group consciousness on political behavior, I investigate the salience of Latino religious identity on perspectives of immigration policy. Based on current literature, it appears that when respondents attend church often, or identify as being a part of the Protestant or Catholic church, they are more likely to have conservative political preferences. I apply this conceptualization specifically to Latinos, analyzing those who identify as having a sense of linked fate, and interpreting the salience of religious observance by reviewing opinions on immigrant population levels. Observing preferences of immigration among Latinos who have a sense of linked fate, during a period of high deportations and tension within this community, the responses may reflect considerations of religious group consciousness. If conservative policies are preferable despite negative racial consideration, then these policy preferences may be considered through a lens of religious identity, thereby demonstrating the salience of religious group consciousness. Thus, this analysis proposes that those who have strong indicators of religious observance will also prefer fewer immigrant populations entering the United States.

Hypothesis: Those who identify as Protestant or Catholic, and/or attend corresponding religious services often, will favor immigration policy that advocates for a decrease in this population

\section{Conceptualization and Measurement Strategy}

For the purpose of this study, I will use the ANES 2012 Time Series Study. I choose the 2012 study rather than the more recent 2016 study to take the sociopolitical contexts of the time in account. The time of this study is important to consider because this was the year that there was a record number of deportations (Gonzalez-Barrera 2014) and the Latinos-social movement, the DREAMers, had been at the height of participation and activity. This context illustrates a time of forceful immigration debates that may provide stronger survey responses with regard to Hispanic identity and opinions on immigration. The field of respondents are taken from the population of U.S. citizens age 18 years and older. The unit of observation is United States voters and the sample size consists of 589 respondents when variables are subset to draw from Hispanics self-identifying as having a sense of linked fate. The ANES sampling mode consists of face-to-face interviews with in-person recruitment and interviews conducted from 
respondents derived from stratified sample clusters based on address. The respondents for the internet questionnaire mode of samplings draw from address-based mail and internet recruitment survey techniques.

Views of immigration policy are operationalized in this study by considering various perspectives related to the amount of immigrants being allowed into the United States. The dependent variable that I am choosing for this study is originally a factor measure recoded to numerical values that represent opinions to the question pertaining to the number of immigrants respondents believe should be entering the United States. The variable immigpo_level specifically, seeks to measure respondent opinion on immigration levels asking the question, "Do you think the number of immigrants from foreign countries who are permitted to come to the United States to live should be ....". The answers are coded from decreasing to increasing intervals as 1 . DECREASED A LOT 2. DECREASED A LITTLE 3. LEFT THE SAME AS IT IS NOW 4. INCREASED A LITTLE 5. INCREASED A LOT. This variable is a relevant measure of immigration policy attitudes because it evaluates the respondents' views on stricter immigration policy; lower populations of immigrants are preferable if they believe the presence of immigrants should decrease a lot, or looser immigration policy is preferable if they believe that immigrants should increase a lot. Hood, Morris, \& Shirkey (1997) use the same measure for immigration policy in their evaluation of Latino preferences, further validating the use of this variable.

The limitation of this measure pertain to its broad focus, meaning it does not gage respondent's opinions on specific immigration legislation and policies by explicit policy name.
Additionally, the measure relates to a respondent's view on immigrant population levels which does not directly reflect conservative or liberal thought. As past literature examines, however (Verba, et.al 1993; Layman 1997; Layman \& Carmines 1997; Jones-Correa 2001), conservatives tend to favor stricter immigration regulations while liberals tend to favor looser policies. Therefore, by precedent, this variable acts as the measure for immigration policy preference. Figure 1 provides insight to the distribution of immigpo_level. This distribution is normal and has relatively low variance, presenting another limitation with the data. A majority of respondents have moderate perceptions of immigrant populations believing that the population size should be left the same as it is now. This suggests a level of indifference or apathy within this Latino population towards immigrant groups and towards considerations of group consciousness in general.

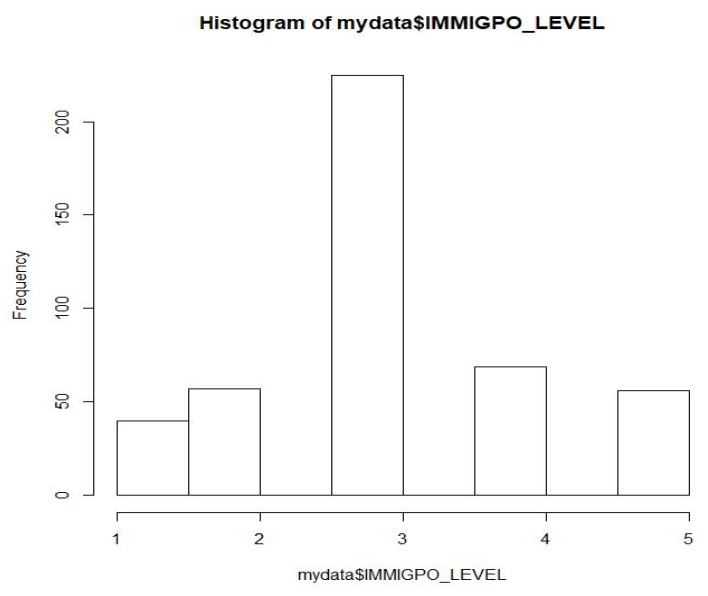

The independent variables of interest are seeking to interpret the intersectional dimensions of the question at hand. The first 
independent variable operationalizes the measure of religious observance. The variable relig_churchoft measures the amount of times that a respondent attends religious services on a continuously increasing scale, coded as: 1 . NEVER 2. A FEW TIMES A YEAR 3. ONCE OR TWICE A MONTH 4. ALMOST EVERY WEEK 5. EVERY WEEK. Verba, et.al (1993) also use a similar measure in their analysis of religion and political involvement. This measure serves as an account for religious observance given that levels of church involvement suggest varying degrees to which a respondent commits to the faith. Further, it serves to interpret the extent to which a respondent identifies with his/her religion and depends on this ideology in normative thinking. This variable serves to operationalize one dimension of religious group consciousness. There are limitations to this variable in which it does not directly account for spiritual commitment or the degree to which the respondent observes the religion apart from attending religious services. Though a respondent may attend church every week, he/she still may not be fully committed to the tenets of the faith.

The second independent variable I observe is relig_group, to account for respondents who identify as Catholics and Protestants. Note that the variable originally contained a "Jewish" and "Other" category that is dropped since the implications of these two sects may vary in effect from that of Catholics and Protestants. This variable serves to measure the amount of respondents who identify with these churches specifically. Kelly $\&$ Kelly (2005) use a similar measure of only Protestants and Catholics in their study of religion and Latino partisanship, further validating the use of this variable. The limitation is that it does not account for specific denominations within these sects and differences of political rhetoric disseminated between these churches. Since the focus of this study is to observe religious salience overall rather than among specific denominations, I choose this variable. Table 1 provides insight to the summary statistics of these independent variables in addition to the main dependent variable. Note that all of these variables are being subset to draw from a specific sample of respondents. The sample draws from those who identify as dem_hisp or Hispanic, Latino, or Spanish in addition to those who identify as having link_hisp or answer YES to the question "Do you think that what happens generally to Hispanic people in this country will have something to do with what happens in your life?"

\begin{tabular}{|l|l|l|l|l|}
\hline $\begin{array}{c}\text { Varia } \\
\text { bles }\end{array}$ & Min & Mean & $\begin{array}{c}\text { Media } \\
n\end{array}$ & Max \\
\hline $\begin{array}{l}\text { Immig } \\
\text { pro_le } \\
\text { vel }\end{array}$ & 1.00 & 3.098 & 3.00 & 5.00 \\
\hline $\begin{array}{l}\text { Relig_ } \\
\text { churc } \\
\text { hoft }\end{array}$ & 1.00 & 2.35 & 2.00 & 5.00 \\
$\begin{array}{l}\text { Relig_ } \\
\text { group }\end{array}$ & 1.00 & 2.323 & 2.00 & 4.00 \\
\hline
\end{tabular}

Table 1

This variable is coded as a dummy variable measuring the number of respondents who answer $\mathrm{YES}=1$ or $\mathrm{NO}=0$. This variable aims to interpret the extent to which respondents have shared sense of linked fate with other Hispanics, suggesting that they too would have a stake in immigration policy. The overall intent of the subset is to specifically distinguish the extent to which religious group consciousness may be salient since all members of the sample have a shared sense of linked 
Controlling for strong political affiliations to either party is necessary to understand the extent to which only religious observations influence perception of immigrant populations. The variable pid_ $x$ indicates the partisanship of the respondent and serves as a control variable. The variable is coded on a scale of 1 to 7; 1 being STRONG DEMOCRAT and 7 being STRONG REPUBLICAN. This variable is problematic in that it encompasses varying degrees of Democrat and Republican support including "liberal Democrats" and "liberal Republicans." These variations leave much room for subjective interpretations of one's party identification. Still, this control is necessary as prior literature has observed the influence of partisanship on immigration policy (Verba et.al [1993]; Layman [1997]; Layman \& Carmines [1997]). Controlling for partisanship on any scale is necessary for this analysis to accurately distinguish the salience of religious identity. Further, the variable dem_edu categorizes respondent's highest level of educational achievement, serving as a second control. Accounting for different perceptions of immigrants based on education level is common in literature on the subject of political participation. Particularly on the subject of Hispanic policy preferences and immigration policy, the use of this variable is exemplified by Hood, Morris, \& Shirkey (1997). Additionally, accounting for education in the study of group identity is necessary because perceptions of group consciousness are influenced by variations in educational attainment (Miller, A. H., Gurin, P., Gurin, G., \& Malanchuk, O. 1981) interpreting the extent to which the dependent variable, immigpo_level, changes in response to the two independent variables relig_churchoft, and relig_group. Together, these variables operationalize religious group consciousness in tandem to perceptions of immigration. By using these measures, I interpret religious identity on dimensions of behavior and affiliation. The model established evaluates the salience of religious group consciousness in the context of Latino immigration policy preferences. I run a linear regression analysis using the R-Studio coding software to configure the model below:

$$
\begin{gathered}
\text { Model }=\operatorname{lm}(\text { immigpo_level } \sim \text { relig_churchoft } \\
+ \text { relig_group }+ \text { pid_X }+ \text { dem_edu })
\end{gathered}
$$

Though the variables included in this model are justified by literature, there are still clear limitations. When considering the model's ability to fully configure religious group consciousness, the framework of "group consciousness clusters" as used by Gabriel Sanchez (2006) could be of better use. This framework may also account for religious salience across pan-ethnic Latino groups. However, for the purpose of this study which is a preliminary analysis of group consciousness, I choose a simple linear regression model. Additionally, the measure of relig_group does not account for cross denominational affiliations, revealing a caveat in the models ability to fully interpret religious observation. Likewise, the control variable indicating partisanship is slightly problematic in that it leaves room for respondent bias of party identification that may influence results. Further, the dependent variable, immigpro_level, could be better operationalized by reference to a specific policy measure in its 
question. Nevertheless, similar variables are used amid literature on topics of religion, Latino group consciousness, and immigration, validating its use for the purpose of this study. Further, though there is research pertaining to the aforementioned political discourses, it is important to note that conversation on the subject of Latino religious group consciousness, and implications for immigration policy and political mobilization have been overlooked, further validating the preliminary use of these variables for this analysis.

\section{Results \& Analysis}

The results of Table 2 illustrate an interesting dynamic between this combination of variables. As seen, the P-values for Latinos who attended church often (relig_churchoft) and those who affiliate with either Catholic or Protestant churches (relig_group), diverge greatly from the .05 threshold thereby disconfirming the proposed hypothesis. The salience of Latino religious group consciousness on political preference, specifically on the topic of immigration, is thus largely insignificant. As plausibly expected, the control variables, in particular that of education, employs significant statistical effect on perspectives of immigrants. Surprisingly, the direction of this effect, seen in the coefficient plot Figure 2, does not follow conventional thought. The probability estimate predicts opinions favoring a decrease in immigrants for every increase in educational attainment. For both dependents, the variable crosses over the 0.00 threshold for regression estimates.
Adjuste
Estim
Std.
ate
Error

\begin{tabular}{|c|c|c|c|c|}
\hline $\begin{array}{c}\text { Intercep } \\
t\end{array}$ & 3.413 & .313 & $\begin{array}{c}10.87 \\
9\end{array}$ & $\begin{array}{l}<2 e-1 \\
6 * * *\end{array}$ \\
\hline Church & -0.00 & 0.052 & -0.03 & 0.969 \\
\hline $\begin{array}{c}\text { Attenda } \\
\text { nce }\end{array}$ & 2 & & 9 & \\
\hline Christia & 0.080 & 0.061 & 1.316 & 0.189 \\
\hline $\begin{array}{c}n / \text { Catho } \\
\text { lic }\end{array}$ & 8 & 4 & & \\
\hline Party & 0.065 & 0.031 & 2.076 & 0.038 \\
\hline $\begin{array}{c}\text { Identific } \\
\text { ation }\end{array}$ & 2 & 4 & & * \\
\hline Educati & -0.06 & 0.021 & -3.18 & 0.001 \\
\hline on Level & 75 & 2 & 6 & $* *$ \\
\hline
\end{tabular}

Table 2

Those who attend religious services often have an estimate of .002 in favor of less immigrants entering the country. Though this is rather insignificant, the negative sign supports the hypothesized influence for religion. According to these data, those who attend services more often, favor conservative immigration policies attuned to decreasing immigrant populaces in the US. Interestingly however, those who identify as being Christian/ Catholic have an estimate equal to .0808 , revealing an insignificant however positive view in favor of more immigrants. If one identifies as Christian/ Protestant, then he/she is also more likely to support immigration policy that favors increasing the number of immigrants entering the country. The adjusted $\mathrm{R}^{2}$ value of about $4 \%$ reveals that the model explains for only some variation in perceptions of immigration policy. 


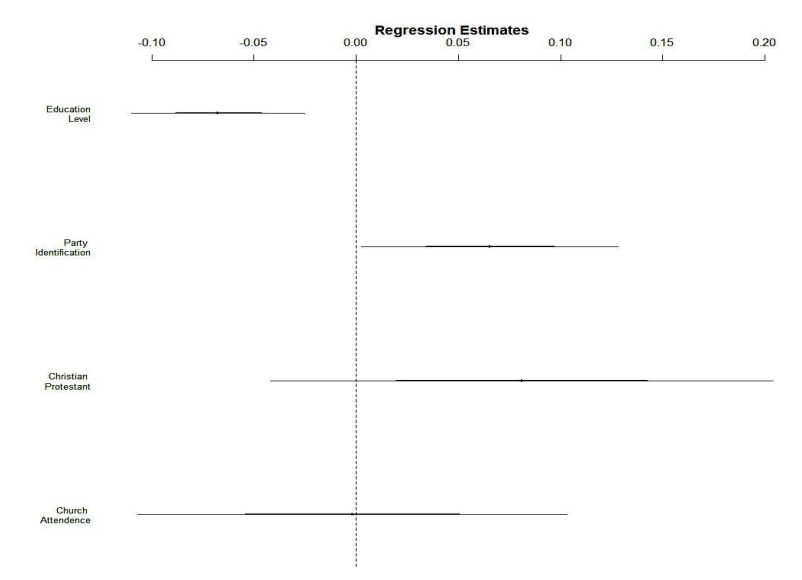

From these data, we can draw some inferences about the salience of Latino religious group consciousness on the subject of immigration. It is plausible that attending church more often associates with increased religious group identity, serving as explanation for why they prefer less immigrants in the country. Active church attendance may provide a sense of community, and the political rhetoric expressed within these church communities overall have been historically conservative. This serves as an explanation for the results indicating a favor for less immigrants entering the United States. Identifying as either Protestant/ Catholic may result in opposite opinions because of the construction of the variable. Since the data only accounts for those who self-identify as Christian/Protestant and not for denominational associations within these Churches, there is room for subjective interpretations of religious affiliation. Some denominations may be more liberal or conservative than others, for example evangelical and mainline identifying Protestants have a greater sense of Republican partisanship than do Catholics (Kelly \& Morgan 2005). If the sample analyzed represents more Catholics than Protestants, then these differences of partisanship between denominations may account for the liberal perspectives given about immigrants.
The difference in opinions Figure 2 between those who attend services often and those who identify as being affiliated with a church interestingly suggests that indicators of religious observance are more salient than indicators of religious affiliation when operationalizing religious group consciousness. Though past research has assumed religious affiliation (religious sect) to have the same effect as religious observance (church attendance), this analysis presents clear differences in political opinion between the two. Overall data and knowledge made available on the subjects of religion and Latino group consciousness are limited, thereby restricting this preliminary analysis on the salience of religious group consciousness.

The results presented are not as expected nor hypothesized. Possible explanations for this variance can be attributed to faults in the model as well as limitations of available data as a whole. The findings do not support the hypothesis but rather reveal the malleable intersectional nature of religious identity. Further, I find that differences in opinion between the two independent variables, relig_group and relig_churchoft, imply that variables measuring religious behavior rather than religious church affiliation are better indicators for measuring religious group consciousness. This notion implies that those who have strong religious behavior have more salient sense of religious group consciousness than those who simply identify themselves as a part of a specific religious sect. Based on these observations, it can be concluded that the salience of religious group consciousness overall is rather weak given the large degrees of variance between the variables. This provides insights to the multidimensional 
nature of intersectional identities. Between these identities of race and religion, many subjective contextual conditions may influence political preference. This includes controls such as education, denominational affiliation, income, and general diverging preferences among pan ethnic Latinos.

\section{Conclusion}

Insight on Latino policy preference and the role of religion in shaping these sentiments is important to consider as the influence of Latinos in the political sphere grows. This group forms the largest growing population of immigrants in the United States (Lopez, Bialik 2017). Simultaneously we witness growing rhetoric in the political sphere about attracting these minority votes (Alvarez \& Bedolla, 2003). Despite the influences of religion in forming political opinion, research on the topic of religious group consciousness is rather minimal if not completely unexplored. Even more so, within the framework of Latinos and discussions of immigration policy preferences, religious group consciousness is not applied. This analysis seeks to input knowledge on the relevance of religious identity in shaping political opinions. By observing immigration preference, and considering the intersectional nature of race and religious identity, I examine the salience of religion in forming political decisions. The conceptualization of religion within the theoretical framework of group consciousness has rarely been applied in the discourse examining Latinos and immigration policy. By applying this theory to Latinos, I hope to add to the narrative of intersectional identity, ultimately questioning the salience of religious observance indicators to predicting political behavior.

The findings presented can only begin to uncover the role of religious behavior and affiliation on Latino immigration preference. The analysis discovers that religious group consciousness is not salient in forming consistent political preferences on immigration. Though the hypothesis is half supported by the conservative preferences of Latinos who attend church often, those who identify as Catholic and Protestant still observe more liberal interpretations of immigrants. These data present race and religion as complex and multidimensional in the study of policy preference. Latinos who identify as having a sense of linked fate, and fall within a spectrum of religion observation, still vary in their interpretations of immigration. I find that between the indicators of religious observance, variables that measure religious behavior and variables measuring church affiliation, result in sizable differences of political preference. Particularly, religious behavior rather than affiliation is a better indicator and measurement of religious group consciousness.

There are clear constraints with the data made available and used in the model to understand this relationship. Still, the results add to the discussion of religion and political participation by finding differences of preference among the types of religious observance measures. Though the salience of religious group consciousness is not supported by these observations, this analysis suggests that differences of measures of religious identity are important to consider as these definitions may provide different cues of religiosity, thereby resulting in different policy opinions between religious observers. Further research on the subject would perhaps provide more insight to the particular differences between religious observance indicators versus indicators related to religious affiliation. In addition, the exploration of religious group consciousness should be expanded and applied 
to various contexts beyond Latinos and immigration policy to fully interpret the intersectional dimensions of identity and its influence on politics.

\section{Appendix}

Model 1. Distribution of Errors

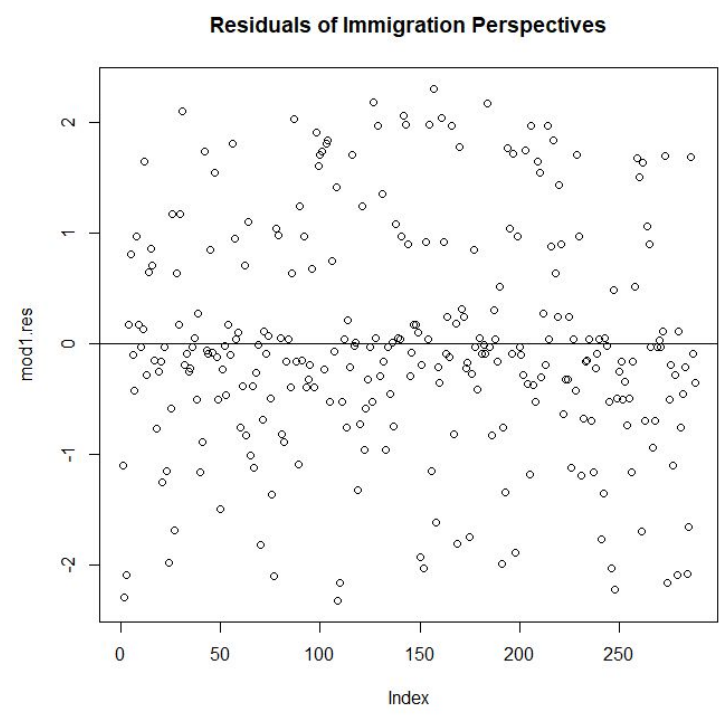




\section{Works Cited}

Alvarez, R. M., \& Bedolla, L. G. (2003). The

Foundations of Latino Voter

Partisanship: Evidence from the 2000

Election. The Journal of Politics, 65(1), 31-49.

Brady, H. E., Verba, S., \& Schlozman, K. L. (1995). Beyond SES: A Resource Model of Political

Participation. American Political

Science Review,89(02), 271-294.

Chavez, Leo Ralph. The Latino Threat:

Constructing Immigrants, Citizens, and the Nation. Stanford University Press, 2013.

Chaves, M., \& Higgins, L. M. (1992).

Comparing the Community Involvement of Black and White Congregations. Journal for the Scientific Study of Religion,31(4), 425.

Dawson, M. C. (1994). Behind the mule: race and class in African-American politics. Princeton, NJ u.a.: Princeton Univ. Press.

García, J. A. (2017). Latino politics in America: community, culture, and interests. Lanham, MD: Rowman \& Littlefield.

Garza, R. O. (1998). Interests Not Passions: Mexican-American Attitudes toward Mexico, Immigration from Mexico, and Other Issues Shaping U.S.-Mexico Relations. International Migration Review,32(2), 401.
Gonzalez-Barrera, A. (2014, January 24).

Record number of deportations in 2012. Retrieved June 24, 2017, from http://www.pewresearch.org/fact-tank/2 014/01/24/record-numberof-deportations-in-2012/

Hood, M. V., Morris, I. L., \& Shirkey, K. A. (1997). "!Quedate o Vente!": Uncovering the Determinants of Hispanic Public Opinion toward Immigration. Political Research Quarterly,50(3), 627.

Jones-Correa, M. A., \& Leal, D. L. (2001). Political Participation: Does Religion Matter? Political Research Quarterly,54(4), 751.

Kelly, N. J., \& Kelly, J. M. (2005). Religion and Latino Partisanship in the United States. Political Research Quarterly,58(1), 87.

Kelly, N. J., \& Morgan, J. (2008). Religious Traditionalism and Latino Politics in the United States. American Politics Research,36(2), 236-263.

Knoll, B. R. (2009). “And Who Is My Neighbor?" Religion and Immigration Policy Attitudes. Journal for the Scientific Study of Religion,48(2), 313-331.

Layman, G. C. (1997). Religion and Political Behavior in the United States: The Impact of Beliefs, Affiliations, and Commitment From 1980 to 
1994. Public Opinion Quarterly, 61(2), 288.

Layman, G. C., \& Carmines, E. G. (1997). Cultural Conflict in American Politics: Religious Traditionalism, Postmaterialism, and U.S. Political Behavior. The Journal of Politics, 59(3), 751-777.

Liu, J. (2014, May 07). The Shifting Religious Identity of Latinos in the United States. Retrieved June 24, 2017, from http://www.pewforum.org/2014/05/07/t he-shifting-religious-identity-of-latinosin-the-united-states/

Lopez, G., \& Bialik, K. (2017, May 03). Key findings about U.S Immigrants. http://www.pewresearch.org/fact-tank/2 017/05/03/key-findings-about-u-s-immi grants/

Lopez, R. (2012). Perspectives on Abortion: Pro-Choice, Pro-Life, and What Lies in between. European Journal of Social Science,27(4), 511-517

Masuoka, N. (2006). Together They Become One: Examining the Predictors of Panethnic Group Consciousness Among Asian Americans and Latinos. Social Science Quarterly,87(S1), 993-1011.

Mcclain, P. D., Carew, J. D., Walton, E., \& Watts, C. S. (2009). Group Membership, Group Identity, and Group Consciousness: Measures of Racial Identity in American Politics? Annual Review of Political Science, 12(1), 471-485.
Mcdaniel, E. L., Nooruddin, I., \& Shortle, A. F. (2011). Divine Boundaries: How Religion Shapes Citizens' Attitudes Toward Immigrants. American Politics Research,39(1), 205-233.

Miller, A. H., Gurin, P., Gurin, G., \& Malanchuk, O. (1981). Group consciousness and political participation. American Journal of Political Science, 25, 494-511.

NIV Bible. (2007). London: Hodder \& Stoughton Ltd.

Sanchez, G. R. (2006). The Role of Group Consciousness in Political Participation Among Latinos in the United States. American Politics Research,34(4), 427-450.

Stokes, A. K. (2003). Latino Group Consciousness and Political Participation. American Politics Research,31(4), 361-378.

Vargas, E. D., Sanchez, G. R., \& Valdez, J. A. (2017). Immigration Policies and Group Identity: How Immigrant Laws Affect Linked Fate among U.S. Latino Populations. The Journal of Race, Ethnicity, and Politics, 2(01), 35-62.

Vega, I. (2014). Conservative Rationales, Racial Boundaries: A Case Study of Restrictionist Mexican Americans. American Behavioral Scientist,58(13), 1764-1783. 
Verba, S., Schlozman, K. L., Brady, H., \& Nie,

N. H. (1993). Race, ethnicity, and

political resources: Participation in the

United States. British Journal of

Political Science, 23, 453-497. 